\title{
Document Summary Description Synopsis
}

National Cancer Institute

\section{Source}

National Cancer Institute. Document Summary Description Synopsis. NCI Thesaurus.

Code C71142.

A text that abstracts the salient information from the document summary description. 